\title{
Fukushima and Chernobyl: similarities and differences in the behavior of radiocesium in soil-water environment
}

\author{
KONOPLEV A. $\mathrm{V}^{1}$ \\ ${ }^{1}$ Institute of Environmental Radioactivity, Fukushima \\ University, Kanayagawa 1, Fukushima, Fukushima \\ Prefecture, 960-1296 Japan, e-mail: \\ alexeikonoplev@gmail.com
}

The ease with which radionuclide moves through the environment and is taken up by plants and animals is determined by its chemical forms and site-specific environmental characteristics [1]. The peculiarities in climate, geomorphology and ${ }^{137} \mathrm{Cs}$ speciation in the fallout were demonstrated to lead to differences in migration rates of ${ }^{137} \mathrm{Cs}$ in the environment and rates of its natural attenuation. It has been revealed that the Fukushima-derived ${ }^{137} \mathrm{Cs}$ is strongly bound to soil and sediment particles, which reduces potential bioavailability of this radionuclide [2]. Up to $30 \%$ of the deposited ${ }^{137} \mathrm{Cs}$ on soil of the exclusion zone were found to be incorporated in hot glassy particles ("Cs balls") insoluble in water [3]. These particles are decomposing in the environment essentially slower as compared with Chernobyl derived fuel particles [4]. Wash-off from the slopes of contaminated catchments and river transport are key longterm pathways for radionuclide dispersal from contaminated areas after the Fukushima accident. The climate conditions for the Fukushima Prefecture of Japan are characterized by higher annual precipitation (1300-1800 mm/year) with maximum rainstorm events during typhoon season. Typhoons Etou in 2015 and Hagibis in 2019 demonstrated the substantial redistribution of ${ }^{137} \mathrm{Cs}$ on river watersheds and floodplains and in some cases natural self-decontamination [5]. Steep slopes of Fukushima catchments are conducive to higher erosion and higher particulate r-Cs wash-off. Irrigation ponds in Okuma and Futaba towns demonstrated persistent behavior of ${ }^{137} \mathrm{Cs}$ similar to closed lakes in Chernobyl, its concentrations not decreasing and showing regular seasonal variations: the ${ }^{137} \mathrm{Cs}$ concentrations tend to grow in the summer and decrease in the winter.

[1] Konoplev et al. (1992) Analyst 117, 1041-1047. [2] Konoplev et al. (2016) J. Environ. Radioactivity 151, 568578. [3] Ikehara et al. (2018) Environ. Sci. Technology 52, 6390-6398. [4] Okumura et al. (2019) Sci. Reports 9: 3520. [5] Konoplev et al. (2018) J. Environ. Radioactivity 186, 2333. 